\title{
Currículo e espaço - uma conversa por se fazer?
}

\author{
Ana Angelita Rocha ${ }^{1}$ \\ ORCID: 0000-0001-8142-0119 \\ Ricardo Scofano Medeiros ${ }^{1}$ \\ ORCID: 0000-0002-9015-9853
}

\section{Resumo}

As páginas a seguir ensaiam uma cartografia (múltipla, nas inspirações de Doreen Massey (2004) e Deleuze; Guattari (2011)) propondo traçar possíveis associações entre currículo e espaço. A intenção deste artigo é especular que, ao campo curricular, importa o ato de espacializar a relação entre currículo e conhecimento. Tal objetivo implica um projeto de interrogar um pretenso conhecimento universal, sem que, necessariamente, a categoria conhecimento seja desprezada como um todo. Por esse motivo, a argumentação, a partir de teóricos do currículo e da geografia, permite perceber um encontro entre a epistemologia, a ontologia e o espaço. Contudo, nossa hipótese é a de que o campo curricular pouco se dedica ao debate espacial, ainda que seja uma categoria analítica emergente nos seus estudos. Embora haja uma leitura de teóricos do espaço, suspeitamos que tenham sido conversas interditadas. Não obstante, nossa leitura permite vislumbrar uma convergência que parece indicar o espaço como uma categoria ontológica do currículo. Tais movimentos foram disparados por uma pergunta que guia o texto em seus desdobramentos: o que pode a composição currículo e espaço?

\section{Palavras-chave}

Teorias de currículo - Espaço - Conhecimento.

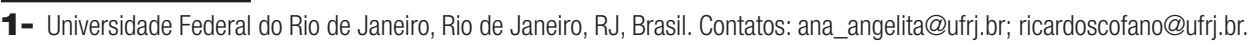




\section{Curriculum and space - a conversation to be done?*}

\section{Abstract}

The following pages attempt a cartography (multiple, as inspired by Doreen Massey (2004) and Deleuze; Guattari (2011)), proposing to trace possible associations between curriculum and space. The intention of this paper is to check whether the spatialization of the relationship between curriculum and knowledge matters in the field of curriculum. Such objective implies a project of questioning a supposed universal knowledge without necessarily discarding the category of knowledge as a whole. For this reason, the argument, as from curriculum and geography thinkers, allows the perception of an encounter among epistemology, ontology, and space. However, our assumption is that the field of curriculum has devoted little to the spatial debate despite it being an emerging analytical category within its studies. Although there is a reading of space thinkers, we suspect that conversations have been banned. Nevertheless, our reading allows envisioning a convergence that seems to point space as an ontological category of curriculum. Such movements were triggered by a question that leads the text to its unfolding: what can the combination of curriculum and space do?

\section{Keywords}

Theories of curriculum - Space - Knowledge.

\section{Introdução}

A época atual seria, talvez de preferência, a época do espaço. Michel Foucault (2001, p. 411).

Em 2002, Alfredo Veiga-Neto tomou de empréstimo esse diagnóstico de Foucault (feito na Conferência Outros espaços, em Berlim, 1967) e o converteu em epígrafe, objeto de discussão de um texto atualíssimo acerca da teoria curricular. Com o título De geometrias, currículos e diferenças, Alfredo Veiga-Neto escreveu talvez o mais geográfico texto de (teoria ou) interpretação curricular, convidando a interlocuções de geógrafos como David Harvey e Edward Soja. Do nosso ponto de vista, aquele artigo - ao encorajar a leitura espacial foucaultiana - abriu um caminho para uma discussão por se fazer: a relação entre o espaço e o currículo.

Uma conversa por se fazer, porque carregamos a suspeita de que o campo já se dedicou a contundentes debates sobre currículo e tempo e a correlação entre currículo e cultura. Assim como Veiga-Neto em 2002, concordando com o Foucault de 1967, reiteramos a proposição de que é tempo de se pensar o espaço. Nesse sentido, nosso 
intento perpassa pela problematização do pensamento curricular para, no nosso ponto de vista, sondarmos as potências de que o espaço seja pensado enquanto uma categoria ontológica do currículo.

Na zona de vizinha dessa problemática, situa-se, como veremos no decorrer deste texto, a densa interface entre currículo e conhecimento. De partida, entendemos que perguntas como - Conhecer o quê? Conhecer como? Ou que deve ser isso que, comumente, se chama de conhecimento, por vezes, reificado como base comum? - sejam disparadores que podem, incialmente, aguçar a curiosidade de nossos leitores e leitoras. Nossa escrita suspeita que, entre essas perguntas atravessadas de propósitos curriculares, há uma implicação espaço-temporal.

Em consonância com essa suspeita, vislumbramos a cartografia (DELEUZE; GUATTARI, 2011; RANNIERY, 2012) como caminho investigativo não métrico, não quantitativo, que permite desenharmos com mais nuances o espaço intensivo com o qual pretendemos trabalhar. Em outras palavras, a cartografia como método de pesquisa agencia indícios de diferentes campos de força (geografia, filosofia, educação), geradores de múltiplas relações, que podem contribuir para apontarmos para o caráter interrelacional do espaço - o espaço é mais do que uma mera superfície onde histórias se desdobram. Portanto, nossa suspeita do espaço enquanto categoria ontológica é tributária de uma cartografia curricular.

Para os interesses deste artigo, nossa argumentação é desenvolvida em duas partes. Iniciamos, então, com a pergunta Currículo, conhecimento e espaço: uma composição poderosa?, desenvolvida na seção que interroga o lugar do espaço nas teorizações curriculares. Nessa seção, com base em um painel acerca da proposição currículo-espaçoconhecimento, insinuamos que o reposicionamento desse debate passa pela revisão da caracterização do conhecimento. Por essa razão, parece-nos cara a estratégia de estabelecer diálogos com os teóricos de tendência pós-estruturalista para a leitura da relação espaço e poder, presente em Foucault, por exemplo.

$\mathrm{Na}$ segunda seção, Conhecimento-transporte e conhecimento-peregrino: outro binarismo?, reivindicamos o espaço como categoria ontológica para o pensamento curricular, ao ensaiarmos, com nossos interlocutores teóricos, outras inspirações a respeito do debate curricular que interroguem os binarismos e as reduções do espaço à superfície, inscritas em tentativas de definir o conhecimento.

Talvez, também motivados pela potência dessa relação, consideremos que uma metáfora, ou no dizer de Doreen Massey (2017), uma imaginação geográfica cause uma síntese provisória acerca do que consideremos como associação da teoria curricular ao espaço, de maneira mais intensa. Nossa metáfora está no protagonismo do espaço em Fritz Lang, em especial no filme Metropolis (FRITZ LANG, 1927). Na ficção científica, cuja narrativa fílmica se passa em 2026, a cidade cindida entre trabalhadores e privilegiados, a segregação urbana fala, atua, diverge, portanto, produz imaginações geográficas. Metropolis é seminal para a nossa discussão, porque o espaço-tempo protagoniza os agenciamentos. Em Metropolis, o espaço é ontológico. Coincide com essa leitura a reflexão de Byrne (2003), para quem: "Metropolis é, como o título indica, um retrato fílmico de 
uma cidade; as relações sociais que ele contém são representadas em sua arquitetura e em suas formas”. (BYRNE, 2003, p. 5).

Figura 1 - Reprodução do pôster original do filme Metropolis

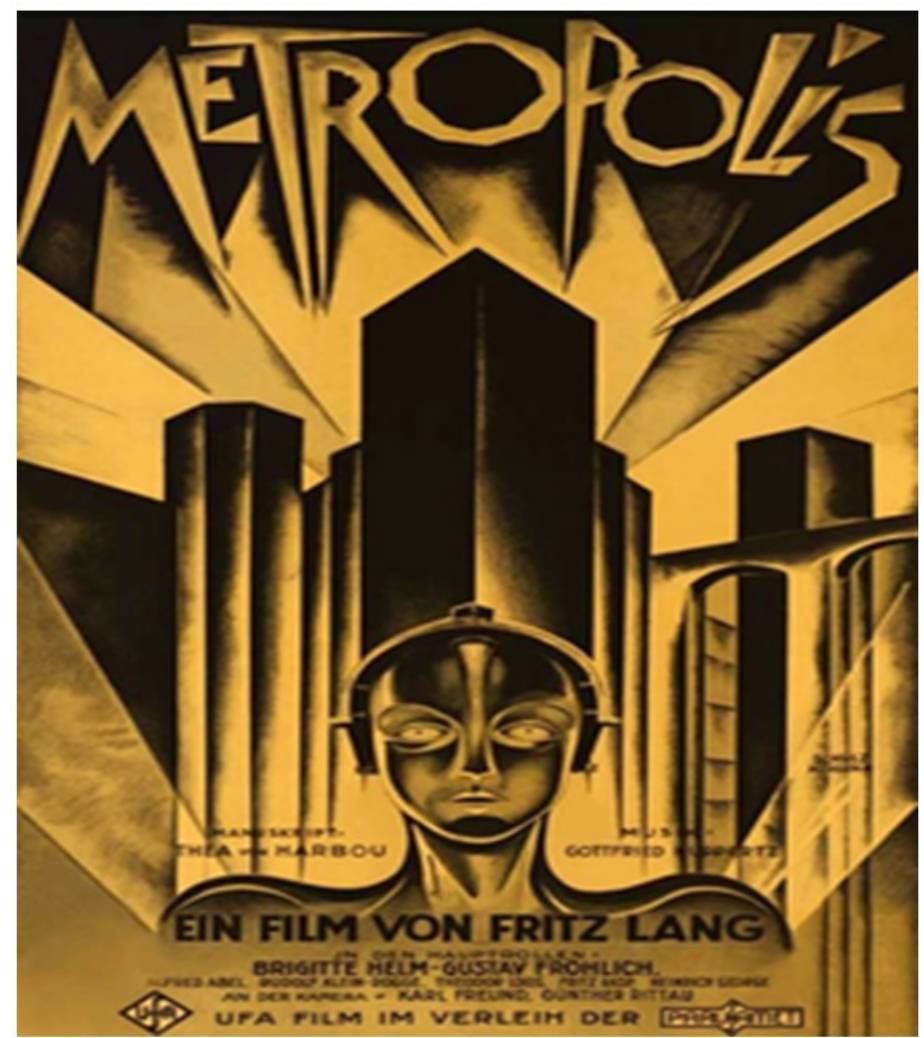

Fonte: (FRITZ LANG, 1927).

Nossa hipótese é a de que a teoria curricular ensaia, todavia, uma discussão em que o espaço-tempo protagonize nossas leituras. Em outras palavras, reconhecemos a potência de Fritz Lang em converter o espaço cênico em personagem. A imagem, portanto, potencializou uma leitura espacial ao propor a indissociabilidade da relação sujeito e espaço. Essa contribuição permite-nos ensaiar neste texto uma suspeita: a de que carecemos de uma conversa por se fazer, mais a miúde, da relação entre currículo e espaço.

\section{Currículo, conhecimento e espaço: uma composição poderosa?}

A palavra de ordem desta seção, ao que tudo indica, pode ser expressa naquilo que se convenciona chamar de poder. Se concordarmos que a palavra poderoso é uma derivação de poder, teremos alguns caminhos que, com o decorrer da escrita, poderão ser abertos. Dando esse passo para trás, de imediato, seria necessário suspender, ou ao menos traduzir fazendo algumas adaptações, a correlação imediata que a derivação poderosa 
da palavra pode disparar. Perseguir o rastro das palavras poder e poderoso, dependendo de quais linhas de escrita serão cartografadas, ou de quais autores serão mobilizados, contribui para a abertura de um verdadeiro abismo entre uma e outra. Mas, tenhamos calma. Não nos joguemos no abismo se, ao olharmos para ele, ele nos olha de volta ${ }^{2}$. Sem a obrigação de recorrer ao dicionário, se entrevê que o sentido da palavra poderoso se vincula a alguém que, obviamente, é detentor do poder.

Nosso objetivo nesta seção, ao questionar a adjetivação do conhecimento, em especial, as propostas recentes de revisão da teoria curricular de Michael Young (2007, 2014), tenciona como a modernidade opera em termos espaciais com o currículo, a partir da concepção de conhecimento. Para sustentar essa intenção, cabe novamente o diálogo com Veiga-Neto (2002):

\begin{abstract}
Em termos espaciais, o currículo funcionou - e certamente ainda funciona - como o grande dispositivo pedagógico que recolocou, em termos modernos, a invenção grega da fronteira como o limite a partir do qual começam os outros; não propriamente o limite a partir do qual nos perdemos, mas o limite a partir do qual os outros passam a existir para nós, o limite a partir do qual a diferença começa a se fazer problema para nós. Em suma, o currículo contribuiu - e ainda contribui - para fazer do outro um diferente e, por isso, um problema ou um perigo para nós. (VEIGA-NETO, 2002, p. 165, grifos do autor).
\end{abstract}

Essa assertiva de Veiga-Neto (2002) ajuda-nos a problematizar os limites/perigos da caracterização do conhecimento, por vezes, uma operação binária de localização, presente, por exemplo, no antagonismo interpretado por Michael Young, ao oferecer uma distinção entre conhecimento poderoso e dos poderosos (YOUNG, 2013, 2014).

Em outro momento (GABRIEL; ROCHA, 2017), questionamos a trajetória de Michael Young, em seus caminhos para diferenciar conhecimento poderoso e dos poderosos, criticando os próprios escritos que trataram da "estratificação do conhecimento" (YOUNG, 1971). A observação que fazemos aqui é que a tentativa da significação da relação conhecimento e currículo passa por uma tradução da perspectiva espacial.

No nosso argumento, ao diferenciar o conhecimento, considera, sobretudo, uma relação de localização da produção e dos usos do currículo, o que implica, necessariamente, a concepção de poder que emerge no exercício da interpretação curricular. Por essa razão, convém-nos, nesse momento, um diálogo com Foucault (2014) para destacar uma das muitas análises propostas por ele acerca da relação entre poder e espaço:

0 poder deve ser analisado como algo que circula, ou melhor, como algo que só funciona em cadeia. Nunca está localizado aqui ou ali, nunca está nas mãos de alguns, nunca é apropriado como uma riqueza ou um bem. 0 poder só funciona e se exerce em rede. Nas suas malhas, os indivíduos não só circulam, mas estão sempre em posição de exercer esse poder e de sofrer sua ação; nunca são o alvo inerte ou consentido do poder, são sempre centros de transmissão. Em outros termos, o poder não se aplica aos indivíduos, passa por eles. (FOUCAULT, 2014, p. 284).

2- Fizemos aqui referência a um conhecido aforismo de Nietzsche (2015, p. 85): "[...] aquele que luta com monstros deve ter cuidado para não se tornar um monstro. E se você olhar durante muito tempo para um abismo, o abismo vai também olhar para dentro de você". 
Mas, por qual motivo, em territórios curriculares, é estratégico pensar em um poder ramificado, capilar? Afinal, quando se trata de currículo como política de Estado as decisões tomadas não são sempre heterônomas? Não caberia, então, aos teóricos e teóricas de currículo ocupar os centros de decisões na busca por um currículo melhor? Longe de mapear os processos de como um currículo constituiu-se enquanto um documento ofıcial (definitivo e incontestável) e se tal constituição é heterônoma ou não, a mirada que enxerga o poder desde seus laços inter-relacionais tende a suspender o pressuposto poder poderoso, determinante, de uma ação específica.

Assumir que o poder só existe em funcionamento é aceitar, também, que ele só existe em transformação (BUTLER, 2017) e, sobretudo, é aceitar que há processos espaciais aí implicados, isto é: rizomas moventes do poder. Um conhecimento poderoso que se pretende independente dos contextos onde é forjado parece, de partida, ignorar as formulações foucaultianas do poder e, ao mesmo tempo, permite uma lógica determinada do espaço que, a nosso ver, desconhece a multiplicidade constitutiva do espacial em detrimento de um conhecimento deslocalizado, posto que universal, e, por isso mesmo, invariável.

No limite, o conhecimento dito poderoso, quando não tem sua meta alcançada, acaba por lançar a experiência curricular em uma arena fatalista. Nas palavras de Young: “a educação preocupa-se, antes de tudo, em capacitar as pessoas a adquirir conhecimento que as leve para além da experiência pessoal, e que elas provavelmente não poderiam adquirir se não fossem à escola" (YOUNG, 2014, p. 196). Aqui, é a associação entre conhecimento e experiência pessoal que começa não só a emaranhar, mas também a ressaltar o emaranhado entre epistemologia e ontologia.

Como argumenta Derrida (1973), ao propor uma ruptura com o universalismo linguístico e abrir caminho para difference, com a chave de interpretação de que toda tradução é, antes, uma traição, por não mais prometer um sentido unívoco e incontestável.

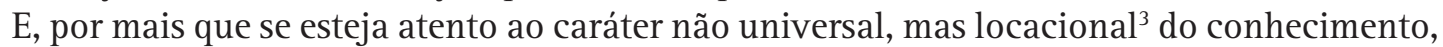
os riscos da universalização não deixam de espreitar.

Nessa altura, as boas intenções podem ser aquelas que nos traem. Por que deveríamos estranhar uma ideia pleiteadora de um conhecimento universal, como aquele conhecimento inquestionável, (des)localizado numa pretensa totalidade? Não seria justamente esse tipo de conhecimento que garantiria, por assim dizer, igualdade entre todos aqueles que o adquirem? Provavelmente, é a partir da intercessão entre essas perguntas que é possível questionar as inter-relações entre currículo, conhecimento e espaço.

Em outras palavras, um sentido do conhecimento universal, abrigado em uma totalidade absoluta, é interditar qualquer possibilidade de localização de quem conhece. $\mathrm{Ou}$ seja, a caracterização de um conhecimento universal seria um conhecimento (des)localizado,

3 - Acerca dessa localização, escreve Haraway (1995, p. 23-24): "a alternativa ao relativismo são saberes parciais, localizáveis, críticos, apoiados na possibilidade de redes de conexão, chamadas de solidariedade em política e de conversas compartilhadas em epistemologia. 0 relativismo é uma maneira de não estar em lugar nenhum, mas alegando-se que se está igualmente em toda parte. A 'igualdade' de posicionamento é uma negação de responsabilidade e de avaliação crítica. Nas ideologias de objetividade, o relativismo é o perfeito gêmeo invertido da totalização; ambos negam interesse na posição, na corporificação e na perspectiva parcial; ambos tornam impossível ver bem." Entendo que estar igualmente em toda parte remete à possibilidade de estabelecer algum tipo de conhecimento universal e, também por esse motivo, descorporificado. 0 final deste artigo tenta distanciar-se dessa tensão entre relativismo e objetividade resgatando outra proposta para que o conhecimento possa ser pensado desde laços inter-relacionais. 
por ser aplicável em qualquer lugar. Eis aqui uma armadilha de classificar a escala do conhecimento como universal. Isto é, qualquer definição escalar do conhecimento, uma base nacional, por exemplo, abriga uma vontade universal, de um conhecimento absoluto.

Recorrer à antropologia, à filosofia, à geografia e aos estudos feministas, nesse momento, deveria se configurar em um movimento esquisito? $\mathrm{Ou}$, nas palavras de Young (2014, p. 196), "por que Derrida? Sem dúvida, trata-se de um filósofo brilhante, mas será que isso significa que ele seja também um teórico do currículo?”. A resposta de Michael Young ao seu próprio questionamento é categórica: "não creio" (YOUNG, 2014, p. 196).

Contrariando a aposta do teórico londrino, a permeabilidade das fronteiras entre o campo das teorias de currículo com demais disciplinas pode, por certo, oxigenar o imaginário curricular e, quem sabe, gerar visibilidades outras para problemas ainda secundarizados na arena do debate curricular. Ousando um pouco: se espaço é uma categoria ontológica da interpretação curricular, então podemos inferir que o imaginário curricular recorre à imaginação geográfica. Em outras palavras, o espaço habitado, vivido, o cotidiano são integrantes da indissociabilidade entre espaço-tempo-currículo.

Essa indissociabilidade implica a escala como variável do fazer curricular uma conversa complicada (PINAR, 2016) também quando é determinada pelo recorte espacial, pois, afınal, todo ponto final do texto curricular, toda decisão curricular é produtora de seleção, é produtora de antagonismos também espaciais. No momento de profundas reformas (ou intenções curriculares), parece-nos conveniente pensar que a escala do currículo não é adjetivo acidental. Ser nacional ou local nas decisões curriculares implica a seleção de sentidos que exclui outras configurações territoriais. Dito de outra maneira: a escala do currículo não é adjetivo menor. É também uma produção do discurso espacial para hegemonizar a decisão curricular.

Nesse sentido, é interessante realizar algumas peregrinações (INGOLD, 2015) por outros espaços (FOUCAULT, 2013). Partindo de uma distinção entre transporte e peregrinação, o conhecimento poderoso, pretensamente universal, é, como veremos, duplamente deslocado.

O peregrino está continuamente em movimento. Mais estritamente, ele é o seu movimento [...] é uma linha que avança [...] em um processo contínuo de crescimento e desenvolvimento, ou de autorrenovação. Conforme prossegue, no entanto, o peregrino tem que se sustentar, tanto perceptiva quanto materialmente, através de um engajamento ativo [...] o peregrino não tem destino final, pois onde quer que esteja, e enquanto sua vida perdure, há algum outro lugar aonde pode ir. (INGOLD, 2015, p. 221, grifo nosso).

0 que deve significar ter outro lugar para ir quando, curiosamente, estamos diante daquilo que é entendido como universal? Em outras palavras, o que deve existir para além do universal, ou "de uma razão universal, de um sujeito único, de uma verdade/ conhecimento válida para todos, [que] ainda marca a educação contemporânea, [e] especialmente o currículo [?]” (TEDESCHI; PAVAN, 2017, p. 679). Os desdobramentos serão diversos, fazendo o conhecimento poderoso devir, quiçá, perigoso. 
Para relançar uma flecha atirada por Nietzsche (2015), é válido lembrar que o bem comum, justamente por ser comum, tem pouco valor. Mas de que forma um bem comum, ou um conhecimento poderoso, capaz de rearranjar experiências pessoais, pode se tornar perigoso? De modo simples e breve, uma resposta pode ser traçada com os escritos de Arturo Escobar (2016).

E, ainda nessa direção, diz Foucault (2014, p. 253): "a descrição espacializante dos fatos discursivos desemboca na análise dos efeitos de poder que lhe estão ligados." Portanto, espacializar o conhecimento poderoso é não só localizar e situar sua universalidade, mas também entender sua funcionalidade na constituição daquilo que Escobar (2016) denominou de Mundo Mundial.

Ao escrever acerca dessa ideia, Arturo Escobar (2016, p. 22) afirma que:

[...] talvez o aspecto medular do Mundo Mundial seja a divisão ontológica: uma forma específica de separar a humanidade da natureza (a divisão natureza/cultura) [...] constituindo a base de uma estrutura institucional [...] através da qual se coloca em ação o Mundo Mundial.

Ora, não deveria ser produtivo, para pesquisadores e pesquisadoras implicados no campo do currículo, perscrutar a divisão entre natureza e cultura? Em um passeio rápido, sem a menor pretensão de esgotar os binarismos disparados, podemos entreolhar a miríade de dualismos correlatos a tal separação: civilizado, selvagem; desenvolvido; subdesenvolvido; eu, outro; bom aluno, mau aluno; inteligente, burro etc. Desse modo, assim como defendem Tedeschi e Pavan (2017):

[...] partimos do entendimento de que o currículo, a educação, precisam problematizar a predominância de um modo de existência universal que tende a frustrar a emergência de outros modos; precisa considerar que vivemos num mundo pleno de possibilidades e que deixar o outro ser um outro singular, ser aquilo que ainda não foi inventado, potencializa outros modos de vida. (TEDESCHI; PAVAN, 2017, p. 679).

E, nessa mesma perspectiva, ouvimos os ecos da pergunta formulada por Butler (2013, p. 161): "que relação entre conhecimento e poder faz que nossas certezas epistemológicas acabem servindo de suporte a um modo de estruturar o mundo que oblitera possibilidades de ordenação alternativas?".

Suspeitamos que, como pano de fundo, a conjunção de um Mundo Mundial e a defesa de um conhecimento poderoso atua de modo a gerar uma concepção específica de espaço que serve, literalmente, como superfície onde é possível erodir e exterminar outras formas de vida, e, por que não, outros mundos. Dito isso, importa sublinhar que "o entendimento do mundo é muito mais amplo que o entendimento ocidental do mundo." (ESCOBAR, 2016, p. 16). Sendo assim, é na prática de um exercício teórico, mas não menos material, que é possível cartografar o surgimento de vozes e mundos dissonantes que, por direito, localizam aquilo que é tido como universal.

0 que se desenvolveu dentro do projeto de modernidade, em outras palavras, foi o estabelecimento e a (tentativa de) universalização de uma maneira de imaginar o espaço (e a relação sociedade/ 
espaço) que afirmou o constrangimento material de certas formas de organizar a relação entre sociedade e espaço. E que ainda permanece hoje em dia. (MASSEY, 2015, p. 103).

De certo, nossa reinvindicação de uma conversa entre espaço e currículo é atravessada por concepções de espaço que rejeitam um sentido de espaço como superfície. Por essa razão, parece-nos oportuno o projeto de revisão da concepção do espaço que, de acordo com Massey, passa pela recusa do fundamento último e da cisão espaço-tempo. Massey (2015) procurou, assim, enaltecer a multiplicidade, a contingência e, não por acaso, questionou as perspectivas que concebem o espaço como absoluto (em especial as que compreendem a totalidade com fenômeno encerrado) e com isso, as que procuram a definição de representação do espaço como apreensão objetiva do real. Entendemos que o projeto de concepção de espaço em Massey (2015) prioriza o debate político-discursivo,

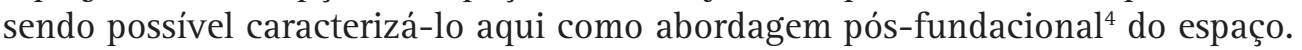

Tanto nos ensaios da década de 1990/2000 quanto na sua obra traduzida como Pelo espaço, é possível identificar uma proposição substantivamente política na abordagem do espaço/espacialidade, termos empregados e definidos por ela como intercambiáveis (MASSEY, 2004, 2015). Ou seja, textualmente como substantivo e verbo, espaço/ espacialidade/espacializar são concepções que ritualizam a coetaneidade, o que para a autora seria a impossibilidade de representar a vida. Podemos ler aqui que há uma forte sugestão para compreender os efeitos de sentido de espaço que, por sua vez, escapariam a qualquer tentativa ou estratégia de representação, de captura, de imobilidade. Nas palavras da autora:

0 espaço é a esfera da possibilidade da multiplicidade na qual distintas trajetórias coexistem, é a esfera da possibilidade da existência de mais de uma voz. Sem espaço não há multiplicidade, sem multiplicidade não há espaço. Se o espaço é indiscutivelmente produto de inter-relações, então, isto deve implicar na existência da pluralidade. Multiplicidade e espaço são co-constitutivos. (MASSEY, 2004, p. 8).

Massey, com efeito, nesta citação, valorizou a multiplicidade como pauta de interpretação do espaço que incorpora a contingência, afastando-se do modelo explicativo de autorização da dicotomia espaço e tempo, o que, de certo, está a favor da pauta da democracia radical (MASSEY, 1992). A garantia de que não há multiplicidade sem espacialidade, e vice-versa, absorve uma qualidade de crítica às formas essencialistas que propõem o esvaziamento de uma abordagem da justaposição, de rizomas e de incompletudes presentes em abordagens teórico-metodológicas "mais próximas" ao pós-estruturalismo.

0 duplo deslocamento do conhecimento poderoso consiste, então, na destituição de seu status universal e, por outro lado, em trazer à tona, com o estabelecimento de um

4- Pós-fundacionalismo, de acordo com Marchart (2009), pode ser compreendido como perspectiva teórica que defende a constituição da contingência e das disputas de sentidos na interpretação do fenômeno político. Em suma, o pensamento pós-fundacional contesta o fundamento, mas não o nega, reforçando assim a luta pela duração, pela contingência do fundamento. "A dissolvência dos marcos das certezas" (LEFORT, apud MARCHART, 2009, p. 19) seria o projeto epistemológico que une as teorias pós-fundacionais. Com essa definição de pensamento pósfundacionalista, Marchart (2009) cita os estudos de Heidegger, Wittgenstein, e mais na segunda metade do século XX, a proposta da teoria da hegemonia de Ernesto Laclau, por exemplo. 
mapa (DELEUZE; GUATTARI, 2011), o sem-fundo (LAPOUJADE, 2017) daquilo que parecia estável, consolidado e pronto para "entreg[ue] à próxima geração" (YOUNG, 2013, p. 226). Dito de outro modo, a tarefa consistiria em uma cartografia dos:

[...] nexos particulares entre poder e conhecimento que criam um campo de objetos inteligíveis, [rastreando] o ponto em que este campo beira o colapso, os momentos de suas descontinuidades, os locais em que a inteligibilidade que tanto sustenta, ameaça caducar. (BUTLER, 2013, p. 173).

Até agora, pontuamos outra concepção de poder (FOUCAULT, 2014) que, menos do que ressoar ares deterministas que os atos poder engendram, aponta, antes, para sua dimensão produtiva: o poder produz. 0 poder produz e é produzido por espaços e, a partir de agora, a atenção deste texto voltar-se-á mais especificamente para os nexos espaciais sinalizados anteriormente. Nesse sentido, a distinção entre peregrinação e transporte será valiosa e desenvolvida com maior propriedade. Ou, nas palavras de Doreen Massey (2012, p. 134): "o que está em questão, pois, é tanto a maneira de organizar o espaço e de controlá-lo, como a maneira de conceituá-lo”.

Por esse motivo, nosso esforço nesta seção foi compreender o espaço, conhecimento e currículo como potente composição. Nesse sentido, ensaiamos os limites de qualificar o conhecimento como fator locacional, ao apresentarmos criticamente a visão de reduzir o espaço ao absoluto, à representação métrica. Apostando na abertura do espaço, seguindo as problematizações de Massey $(2004,2015)$, procuraremos na próxima seção ensaiar a possibilidade de reconfigurar currículo e espaço, como categoria ontológica.

\section{Conhecimento-transporte e conhecimento-peregrino: outro binarismo?}

Um dos efeitos da modernidade foi o estabelecimento de uma relação poder/conhecimento determinada que se refletia em uma geografia que era, por sua vez, uma geografia do poder (poderes coloniais/espaços colonizados). (MASSEY, 2012, p. 137).

Além disso, o currículo contribuiu para a espacialização do tempo, isto é, para o entendimento de que o tempo é redutível ao espaço, pode ser pensado em função do espaço, na medida em que passou a ser visto como rebatível ao espaço. (VEIGA-NETO, 2002, p. 165).

Iniciamos esta seção com duas citações que devem ser lidas no conjunto de nossa suspeita: a de que (enquanto intérpretes de currículo e espaço) precisamos conversar. Doreen Massey (Geógrafa britânica, falecida em 2016) alertava-nos dos efeitos de sentido da modernidade sobre o espaço: a construção de uma ciência (geográfica) que produziu uma relação entre conhecimento e poder subordinada ao projeto colonial ${ }^{5}$. Veiga-Neto

5- Para Massey (2004, p. 14), a escola do estruturalismo francês influenciou a conversão do espaço em tempo, particularmente na construção de classificações, ou tipologias da Antropologia, cuja utilidade dos modelos explicativos se fundava em pares adjetivos como "primitivos-civilizados". $\mathrm{E}$, de acordo com a autora, o prodígio do estruturalismo teria sido promover estruturas a - temporais como espacialidade, consagrando 0 divórcio entre 0 espaço e o tempo. 
(2002) denuncia que a modernidade produziu um currículo que subordinou o tempo ao espaço, implicando uma relação binária ao invés da indissociabilidade, ansiada pela apreensão da filosofia política da espacialidade de Doreen Massey (2004).

Interessante observar que Doreen Massey (2015) identificou que as ciências sociais, em especial a antropologia, operou o espaço como categoria ôntica, mensurável e subordinada ao tempo. Ela desenvolveu essa reflexão identificando os limites das apropriações de Bergson, Laclau e Levis Straus, entre outros ícones das humanidades no século XX. Esse ponto da argumentação espacial de Massey desafia-nos a (re)pensar:

[...] que o que é necessário é arrancar o "espaço" daquela constelação de conceitos em que ele tem sido, tão indiscutivelmente, tão frequentemente, envolvido (estase, fechamento, representação) e estabelecê-lo dentro de outro conjunto de ideias (heterogeneidade, coetaneidade, caráter vivido, sem dúvida) onde seja liberada uma paisagem política mais desafiadora. (MASSEY, 2015, p. 35).

A citação remete-nos tanto ao estruturalismo - reconhecido por Massey como o paradigma que favoreceu a construção epistemológica e a identificação da disciplina Geografia - bem como à contribuição do pós-estruturalismo, para tornar o político uma referência do espaço. Essa citação procura ilustrar o desafio de se pensar o espaço, de modo que compartilhamos o entendimento de que qualquer exploração sobre o espaço na escola carrega o compromisso de problematizar o que Massey (2004) denomina de paisagem política.

Exercitamos aqui uma convergência de pensar a relação entre espaço e modernidade, construindo um diálogo entre Massey (2004) e Veiga-Neto (2002). Em outras palavras, os intérpretes críticos da modernidade propõem outras lentes para análise de seus respectivos objetos, para além da produção de binarismos e explicações universais. Convém nesse momento a análise de outra citação de Veiga-Neto, que elenca sugestões de agenda para o campo do currículo.

Estou interessado em discutir uma questão que é mais, digamos, de fundo. Em vez de uma engenharia curricular, estou mais interessado na arquitetura curricular ou, talvez seja melhor dizer, estou mais interessado na geometria do currículo. Com isso, eu quero dizer que estou interessado em descrever, examinar e problematizar as relações entre o currículo e as ressignificações do espaço - e também do tempo - que estão acontecendo nisso que alguns chamam de Pós-Modernidade, outros chamam de Modernidade Avançada e outros, ainda, de Segunda Modernidade, Modernidade Líquida ou Modernidade Tardia. A pergunta que aqui mais me interessa pode ser assim formulada: "que tem a ver a organização curricular da educação escolarizada com as transformações espaço-temporais que estão ocorrendo no mundo contemporâneo?" (VEIGANETO, 2002, p. 167, grifos do autor).

Ao propor a arquitetura curricular, Veiga-Neto (2002) interpela seu leitor(a) a reivindicar outros significados de currículo e diretamente reposiciona a relação currículo, espaço e tempo. Tal apreensão retira do currículo sua fixidez da engenharia curricular da prescrição do conhecimento. Ademais, a agenda sugerida por Veiga-Neto no início deste 
milênio é conveniente para os propósitos deste ensaio: reposicionar o currículo é repensar o espaço como categoria ontológica. Daí, portanto, a ironia implícita no título desta seção: Conhecimento-transporte e conhecimento-peregrino: outro binarismo?

Para nós, o título desta seção indica o risco de atualizar e recair em um espaço, outra vez, dual. Mais do que isso, por se tratar de uma conversa complicada (e por se fazer), o perigo consiste em dar dois passos para frente, mas, também, dois para trás. $\mathrm{Ou}$ seja, não sair do lugar. Mas seria isso possível? Se, por um lado, é importante escrutinar a ideia de um conhecimento poderoso, por outro lado, como poderíamos fechar os olhos para a chancela curricular da seleção, legitimação e organização dos conhecimentos? 0 paradoxo reside na percepção de que o currículo é decisão, e, como lembra Laclau (2000), as contenções da decisão fundamentam-se contingencialmente. Em outras palavras, de inspiração de Derrida, a decisão é o momento da loucura.

Afınal, é a partir dos ditos conhecimentos poderosos (ou dos poderosos) que residem os estatutos de verdade nos quais são disputados os delírios avaliatórios (VEIGA-NETO, 2012) transvestidos de vagas nos vestibulares, mercado de trabalho, cursos de mestrado e doutorado. Ou seja, em uma agenda em que currículo seja decisão (política) como seria possível fechar os olhos para essa função (normativa) que regula vidas? Ou ainda, como não fechar os olhos para tal funcionamento sem que, com isso, atualizemos o emprego de uma violência epistêmica?

A saída, talvez, seja de ordem espacial. Isso deve significar que não existe um receituário pronto para ser seguido. Nessa perspectiva, perguntas do tipo "como isso se aplica, como coloco isso em prática?" têm pouco valor. Assim, se o currículo tem uma dimensão espacial e espacializante (PINAR, 2009, 2016; ROY, 2002; VEIGA-NETO, 2002, 2007; ALVES, 2001) é desde essa dimensão que interessa pensar o que pode ser chamado de conhecimento. Para tanto, partimos de duas palavras: método e currere. Embora elas não se remetam imediatamente, partilham sentidos, pois, afınal, "devires são geografia, são orientações, direções, entradas e saídas” (DELEUZE; PARNET, 1998, p. 10). Sentidos, portanto, com ao menos três sentidos: sentido como algo que remeta ao significado, sentido como algo relacionado à direção e sentido como algo que se sente, que é sensível ${ }^{6}$, algo como um campo de intensidades não assinaláveis: "o sentido é divergência, dissonância, disjunção” (ZOURABICHVILI, 2016, p. 67).

A etimologia da palavra método ilustra as interceptações possíveis entre método e currere. Methodos, composta por metá, que significa através de, por meio, e hodós, que significa caminho (PESSANHA, 2013). Ou seja, o método poderia ser pensado como um caminho através do qual um espaço é percorrido e, ao final desse caminho, o conhecimento é obtido. Enquanto currere "indica um foco no entendimento da ação da “corrida” (MILLER, 2014, p. 2047), ou seja, no próprio caminhar. Com o método, o que importa é a ordenação do trajeto e não a trajetória: as contingências são menos encontros do que acidentes. Já “em currere, currículo deixa de ser uma 'coisa' e se torna mais um processo, uma ação, um envolvimento com e no mundo” (MILLER, 2014, p. 2047).

6- A respeito da relação entre sensação e espaço, escreve Deleuze (1999, p. 70): "não há por que perguntar se há sensações espaciais, quais são e quais não são: todas as nossas sensações são extensivas, todas são 'voluminosas'”. 
Aprofundar essa distinção é mais do que mapear as diferenças entre a ideia de método e a ideia de currere. Ao contrário, tal movimento desenha-se no sentido de entender as correlações possíveis entre ambas. Afinal, Pinar $(2009 ; 2016)$ sugere: currere é um método. As imaginações geográficas (MASSEY, 2015) que surgem daí, mas ainda não explicadas, também devem ser marcadas. "A explicação é uma implicação em outra coisa" (ZOURABICHVILI, 2016, p. 41).

No nosso caso, aquilo que se encontra implicado, implicante e complicado é o próprio espaço. Implicado, porque a explicação do conhecimento aciona uma narrativa espacial para se estabelecer, implicante porque retomamos novamente a assertiva de Massey (2004, p. 8), para quem:

[...] sem espaço não há multiplicidade [e] sem multiplicidade não há espaço. [Pois] se o espaço é indiscutivelmente produto de inter-relações, então isto deve implicar na existência da pluralidade: multiplicidade e espaço são co-constitutivos.

Complicado, porque o espaço como uma esfera implicada em si mesma não para de mudar de natureza - o currículo como espaço demonstra uma variedade de modos de expressão do espacial: espaço disciplinar (VEIGA-NETO, 2002), espaço de produção de identidades (SILVA, 2005), espaço-tempo de fronteira cultural (MACED0, 2006) etc.

Em tempo, caberia perguntar o que acontece ao conhecimento quando é tomado pelo espaço, isto é, pela diferença incessante que não para de revolver e rearranjar a existência em direções que não apontam para um fim específico ou último. Com as palavras de Nietzsche (1978, p. 104), acreditamos reverberar, como quem entoa um aforismo, a potência da diferença quando o assunto é conhecimento e currículo, pois:

[...] quem chegou, ainda que apenas em certa medida, à liberdade da razão, não pode se sentir sobre a Terra senão como andarilho - embora não como viajante em direção a um alvo último: pois este não há.

Não seria o andarilho um modo de existência intimamente comprometido com a multiplicidade contingente do espaço?

Nesse sentido, entendemos que a preocupação entre conhecimento e verdade ou, melhor dizendo, entre o pensar como forma de conhecer um mundo verídico - e, por isso mesmo, dado - acaba por apagar toda a multiplicidade do que pode ser compreendido e sentido como currículo ou mesmo formas de atuação política que não necessariamente requerem à linguagem do conhecimento/verdade para se estabelecerem. Ou seja, se o currículo é, por si, vinculado ao conhecimento, acabamos por não colocar em xeque aquilo que funda e atribui identidade ao currículo. Em duas perguntas: o que funda o conhecimento? Estaríamos diante de uma vontade de verdade? Não se trata, contudo, de dizer que dois mais dois são cinco, ainda que, nessa altura, a literatura pudesse fazer suas severas advertências:

E - quem sabe? - não se pode garantir, mas talvez todo o objetivo sobre a terra, aquele para o qual tende a humanidade, consista, unicamente, nesta continuidade do processo de atingir o 
objetivo, ou, em outras palavras, na própria vida e não no objetivo, o qual, naturalmente, não deve ser outra coisa senão que dois e dois são quatro, isto é, uma fórmula; mas, na realidade, dois e dois não são mais a vida, meus senhores, mas o começo da morte. (DOSTOIÉVSKI, 2009, p. 47).

\section{Nesse cenário, remetemo-nos à:}

[...] política da verdade pertence[nte] às relações de poder que assinalam de antemão o que se qualificará ou não como verdade, o que irá ordenar o mundo conforme modos regulares e reguláveis e o que será ou não aceitável dentro de determinado campo de conhecimento. (BUTLER, 2013, p. 171).

Questionar os horizontes normativos do conhecimento, ao contrário do que pode parecer, não é uma forma de disputar um jogo com regras prontas. Isso porque:

[...] se há normas de reconhecimento [...] e essas normas são códigos de operações de poder, então pode se concluir que a disputa sobre o futuro [...] será uma batalha pelo poder que funciona em e através dessas normas. (BUTLER, 2004, p. 30).

Isto é, questionar os horizontes normativos do conhecimento torna possivel a disputa pelas próprias regras do jogo que definem aquilo que conta como conhecimento. Tal movimentação, sendo traduzida para o campo curricular, permite-nos deslocar, por exemplo, a linguagem das mensurações:

[...] que caracterizam os campos de finanças e contabilidade - que incluem avaliações comparadas ao processo financeiro de 'auditoria'-, [pois] criadores de teste e aqueles que os prescrevem desconsideram as nuances, os detalhes bagunçados das vidas vividas. (MILLER, 2014, p. 2051).

No entanto, pode deslocar, também, a linguagem dupla do conhecimento e do fracasso, que, decerto, tem suas dimensões espaciais ${ }^{7}$ e implicações para os conceitos de currículo com os quais podemos operar. Em suma, esse movimento traz à tona "a relação entre os limites da ontologia, o elo entro os limites do que posso ser e os limites do que ouso saber." (BUTLER, 2013, p. 171).

7 - Uma narrativa temporal do currículo poderia contribuir para a metrificação e esquadrinhamento do espaço curricular. Embora não esteja falando especificamente de currículo, esse argumento pode ser visto em Massey (2015, p. 107): "sob a modernidade, não apenas 0 espaço foi concebido como divido em lugares delimitados, como esse sistema de diferenciação foi também organizado de uma maneira particular. Resumindo, a diferença espacial era concebida em termos de sequência temporal. Lugares diferentes eram interpretados como estágios diferentes em um único desenvolvimento temporal. Todas as estórias de progresso, unilinear, modernização, desenvolvimento, a sequência de modos de produção... representavam essa operação [...]. Requalificar eufemisticamente 'atrasado' como 'em desenvolvimento', e assim por diante, não contribui em nada para alterar o significado, e a importação da manobra fundamental: a de tornar a heterogenia espacial coexistente em uma única série temporal". Ora, se a chave para pensar o "atraso" de Estados-nações passa por uma narrativa temporal do espaço, o processo em territórios curriculares não parece ser muito diferente. Os (as) alunos (as), quando colocados na mesma sequência temporal, passam a responder de modo semelhante acerca das expectativas de aprendizagem. "Apesar de essa parecer ser uma ambição atraente e emancipatória, é comum esquecer que, uma vez alcançada a meta" (BIESTA, 2012, p. 815), o espaço passa a ser concebido como superfície, ou mesmo como a "terra prometida" à qual deveríamos chegar. 
Nessa inter-relação em que acontece uma dupla interceptação em que limites do que se pode ser estão condicionados aos limites do que se ousa saber, as preocupações e defesas nervais de Michael Young $(2007,2013,2014)$ em direção à necessidade de que as teorias de currículo tenham como seu objeto preferencial o conhecimento não só são legítimas, mas também fazem sentido. Aqui, é o conhecimento como forma de teorizar o espaço que importa. Isso porque, nas palavras de Haesbaert: "no fundo, nada neste mundo é sem espaço. 0 mundo é espaço. Nossas vidas são espaço, exigem espaço, preenchem espaço, fazem espaço, e se fazem como espaço. Não há saída sem espaço." (HAESBAERT, 2017, p. 286). Pensar em outros espaços é pensar em outros mundos, em outras vidas, e que outras vidas podem fazer outros mundos completamente destoantes de um Mundo Mundial.

Vidas que, por sua vez, podem pensar para além do espaço ${ }^{8}$. Ou mesmo onde a distinção entre vida e mundo, correlata à ideia de que marca fronteiras duras entre sujeito e objeto; ou conhecimento como objeto apropriável por um sujeito (MACED0, 2017), não funcione.

A produção social do inexistente claramente dá conta da desaparição de mundos completos, através de operações epistemológicas relacionadas com o saber, com o tempo, com a produtividade e com formas de pensar sobre escalas e diferenças. (ESCOBAR, 2016, p. 15).

Pensar sobre escalas e diferenças é pensar com o espaço, e é desde um problema escalar que a discussão entre conhecimento, currículo e espaço novamente se atravessa.

Esse atravessamento, quase que como em um passe de mágica, deixa uma pergunta escapar, ou, no mesmo sentido, faz uma pergunta surgir: "qual conhecimento deveria compor o currículo?" (YOUNG, 2014, p. 197). Ora, ainda que tal pergunta não evoque explicitamente o espaço, seria ela, por esse motivo, menos espacial? Se o espaçotempo escolar, para Nilda Alves (2001), pode ser pensado como a dimensão material do currículo, então essa dimensão já se encontra implicante e implicada nas relações de conhecimento que serão estabelecidas nas escolas.

0 problema, contudo, parece consistir em dizer qual conhecimento irá compor o currículo. Haja vista que, no mesmo momento em que isso é feito, o próprio espaço não é pensado como conhecimento, transformando-se, assim, uma superfície onde conhecimentos são depositados: a escola passa a funcionar como um espaço depositário dos conhecimentos. Em outras palavras, a escala local deixa de ser vista como uma dimensão viva, pulsante, na qual se produzem conhecimentos.

\footnotetext{
8- Acerca disso, diz o antropólogo Tim Ingold: "Gostaria de argumentar [...] contra a noção de espaço. De todos os termos que usamos para descrever o mundo em que vivemos, trata-se do mais abstrato, do mais vazio, do mais destacado das realidades da vida e da experiência. [...] Os agricultores plantam suas culturas na terra, não no espaço, e as colhem dos campos, não do espaço. Seus animais pastam pastagens, não espaço. Viajantes atravessam o país, e não o espaço. Pintores armam seus cavaletes na paisagem, não no espaço. Quando estamos em casa, estamos dentro de casa, não no espaço, e quando vamos ao ar livre estamos a céu aberto, não no espaço. Lançando os olhos para cima, vemos o céu, não 0 espaço, e um dia ventoso sentimos o ar, não o espaço. 0 espaço é nada, e porque é nada não pode absolutamente realmente ser habitado." (INGOLD, 2015, p. 215 grifos do autor). Tal concepção remete, certamente, a ideia de espaço como superfície isotrópica, ideia que associa o espaço a uma constelação conceitual específica da "estase, fechamento [e] representação" (MASSEY, 2015, p. 34). Constelação conceitual que, nesse artigo, é deslocada na medida em que espaço se associa, de acordo com Doreen Massey, às ideias de "heterogeneidade, relacionalidade, coetaneidade [...] caráter vívido" (MASSEY, 2015, p. 35). Em suma, a defesa de um mundo sem espaço parece ignorar o próprio caráter espacial do mundo.
} 
A partir de então, outras perguntas poderiam ser realizadas: os limites do que se pode ser não teriam também dimensões espaciais? Nesse sentido, não deveria ser levado em consideração que "a simples possibilidade de qualquer reconhecimento sério da multiplicidade e heterogeneidade em si mesmo depende de um reconhecimento da espacialidade [?]" (MASSEY, 2015 p. 31). Ou ainda, como pensar em currículo e conhecimento sem que o espaço seja excluído e rechaçado como dimensão ativa nessa composição? Quais potências o espaço poderia angariar para que o pensamento pense o impensável? São perguntas que, longe de terem respostas, expressam a vontade de que caminhos sejam abertos.

Desse modo, retomamos o fio da meada tentando entrelaçar diferentes linhas que compuseram esta seção do texto. Pensar o impensável, mais do que significar um voluntarismo e vontade de se dirigir ao limite do pensamento, indica um rearranjo na forma como o pensamento é concebido. Já não se trata de um pensamento que é gerado intencionalmente por um sujeito pensante, mas de uma relação que se estabelece com aquilo que ainda não é pensado. "Encontro é o nome de uma relação absolutamente exterior na qual o pensamento entra em conexão com aquilo que não depende dele." (ZOURABICHVILI, 2016, p. 52). Surpreendente, o espaço surge como a dimensão privilegiada para que encontros aconteçam. Assim, se conhecer está associado ao pensamento, e conhecimento associado ao currículo, quando o espaço é lançado nessa composição, tanto pensar como conhecer viram processos espaciais.

Uma passagem muito generosa do artigo Filosofia e politica da espacialidade: algumas considerações, de Doreen Massey (2004), ao mesmo tempo em que sintetiza o debate promove uma abertura do que pode ser pensado como espaço:

0 argumento é que, para a conceitualização de espaço/espacialidade, é crucial o reconhecimento de sua relação essencial com e de sua constituição através da coexistência da(s) diferença(s)a multiplicidade, sua habilidade em incorporar a coexistência de trajetórias relativamente independentes. Trata-se de uma proposta para reconhecer o espaço como a esfera do encontro, ou não, dessas trajetórias - onde elas coexistem, afetam uma a outra, lutam. 0 espaço, então, é o produto das dificuldades e complexidades, dos entrelaçamentos e dos não-entrelaçamentos de relações, desde o inimaginavelmente cósmico até o intimamente pequeno. 0 espaço, para repetir mais uma vez, é o produto de inter-relações. Ademais, como um resultado disso, e como já foi aqui proposto, o espaço encontra-se sempre em processo, num fazer-se, nunca está acabado. Existem sempre extremidades inacabadas (loose ends) no espaço. Tudo isso leva agora a uma conclusão adicional. Este caráter relaciona1 do espaço, juntamente com sua abertura, significa que o espaço também contém, sempre, um grau de inesperado, de imprevisível. Assim, tal como extremidades inacabadas (loose ends), o espaço sempre contém, também, um elemento de "caos" (do ainda não prescrito pelo sistema) [...] 0 espaço, em outras palavras, é inerentemente ‘disruptivo'. Talvez de forma a mais surpreendente, dadas as conceitualizações hegemônicas, o espaço não é uma superfície. (MASSEY, 2004, p. 17).

Portanto, se o currículo tem uma dimensão inegavelmente espacial, e o espaço é uma dimensão imediatamente incontrolável e imprevisível, o que aconteceria aí ao 
conhecimento? A distinção evocada inicialmente entre transporte e peregrinação pode, enfim, ser desdobrada. Enquanto "o transporte [...] é essencialmente orientado ao destino" (INGOLD, 2015, p. 221), "peregrinar é o nosso modo mais fundamental de estar no mundo" (INGOLD, 2015, p. 224). Na ideia de um conhecimento-transporte, o estudante "mesmo não se move. Ao contrário, ele é movido, tornando-se um passageiro em seu próprio corpo" (INGOLD, 2015, p. 221). Já na peregrinação, o conhecimento pode ser pensado como "caminhos ao longo dos quais a vida é vivida [...] precisamente porque o conhecimento, neste sentido, é aberto e não fechado, porque se funde com a vida em um processo ativo" (INGOLD, 2015, p. 224-237). A ideia de transmissão de conhecimento perde território sem que, necessariamente, o próprio conhecimento seja jogado fora - visto que é o próprio fora do pensamento que o anima. Conhecer torna-se um processo contínuo de engajamento, sempre inacabado e nunca totalizável. Um incômodo, contudo, persiste. Tantas linhas para cair em outro binarismo?

Outro incômodo: como converter o binarismo aparente numa ambivalência potente? Este exercício, sem pretensões de esgotar o espaço, teve a intenção de que, na conjuntura neoconservadora das proposições curriculares, convém produzir uma escrita aspirante à tática de reposicionar perguntas (curriculares). Por isso, as metáforas do peregrino e do transporte em Ingold (2015) inspiram-nos a identificar, inclusive, que seria oportuno repensar o binarismo como uma ambivalência que repercutiria outras abordagens do problema da escala do currículo, por exemplo.

Afınal, como desconstruir o discurso do transporte nas atuais proposições curriculares e ressignificar a potência do peregrino? Não se trata de uma substituição do significado de currículo. Sobretudo, trata-se de inscrever perguntas que incomodam no processo de implementação curricular ou exclamar sobre a infertilidade de uma engenharia curricular? Com efeito, sem a vontade de acomodar o texto, com uma agenda ou uma proposta de matriz para repensar a liga entre currículo e espaço, nossas provocações sinalizam uma vontade de conversar a respeito dessa relação.

\section{Algumas considerações}

Para concluir, interessa-nos (fazer) fugir de uma cisão espaço e currículo. Gostaríamos que este texto chamasse atenção acerca da pobreza de reduzir a relação espaço e currículo à localização (um sistema fechado de posições, ignorando o espaço como uma trama interrelacional não totalizável, mas sim disruptiva). Ousamos tencionar intérpretes do campo currículo, ao insistir que nós não nos ocupamos do espaço nos exercícios teóricos. Por essa razão, este ensaio operou com a insuficiência dos binarismos para problematizar a relação currículo e espaço, defendendo-o como categoria ontológica para os nossos estudos.

Por tais razões, ainda nos parece cara a metáfora fílmica de Fritz Lang, ao fazer, ainda em 1927, da imagem cênica o protagonismo do espaço: os roteiristas, diretor, atores e fotógrafos deslizavam nas performances o devir do espaço. Sendo possível assim, questionar o "espaço que nos mói”, como diria Foucault (1967, 2001), pois, afinal: 
0 espaço no qual vivemos, que nos leva para fora de nós mesmos, no qual a erosão das nossas vidas, do nosso tempo e da nossa história se processa num contínuo, $o$ espaço que nos mói, é também, em si próprio, um espaço heterogêneo. Por outras palavras, não vivemos numa espécie de vácuo, no qual se colocam indivíduos e coisas, num vácuo que pode ser preenchido por vários tons de luz. Vivemos, sim, numa série de relações que delineiam lugares decididamente irredutiveis uns aos outros e que não se podem sobre-impor. (FOUCAULT, 2001, p. 415, grifos nossos).

À plateia de arquitetos alemães, em 1967, Foucault alertava da impossibilidade de delinear o espaço, por não ser possível concebê-lo como fixo, alienável. Ao contrário, vivemos em lugares decididamente irredutiveis, o que implica repensar o espaço como múltiplo e não mais como superfície. Interessante notar que a contribuição geográfica de Foucault aconteceu em Berlim, cidade inspiradora de Thea von Harbour e Fritz Lang para Metropolis, um dos ícones do expressionismo alemão. A segregação urbana, as funções e os processos espaciais falavam em suas formas imagéticas fílmicas.

Afınal, se ainda concordamos com Didi-Huberman (2012 p. 404), para quem "Uma das grandes forças da imagem é criar ao mesmo tempo sintoma (interrupção no saber) e conhecimento (interrupção no caos)", estamos inspirados a pensar que entre currículo e espaço, há atravessamentos sobre o real; e entre currículo e espaço operam, simultaneamente, o sintoma e o conhecimento.

Ainda dialogando com Didi-Huberman (2012), nossa defesa do espaço enquanto categoria ontológica estaria no trânsito entre "sintoma (interrupção no saber) e conhecimento (interrupção do caos)” (DIDI-HUBERMAN, 2012, p. 214), o que fez da imaginação geográfica de Metropolis uma produção de sentido de futuro em que a cidade dita e segrega, em devir. Em outras palavras, Metropolis converteu o espaço cênico em personagem, o que investe em um significado de espaço que não nos reifica e, tampouco, nos dê suas relações para dizer quem somos.

Nossa aposta no espaço enquanto categoria ontológica é desistir do espaço como superfície cênica e assumi-lo como personagem. Tais insinuações sobre o espaço neste texto reivindicam que nossas insurgências acerca das proposições neoconservadoras do currículo requerem o ato de cartografar nossas imaginações geográficas que sustentam a validação do conhecimento verdadeiro. Isto porque parece-nos que repensar o espaço no campo curricular exige-nos refletir acerca de sua relação com o conhecimento.

Convém sublinhar que nosso exercício não propôs uma matriz para relação currículo e espaço, ao contrário, entendemos que são múltiplos caminhos para leitura espacial do currículo. Por tais motivações, parece-nos preciosa a distinção de Veiga-Neto (2002) entre engenharia curricular e arquitetura curricular. 0 que nos impele a levar a sério o fato de que o pensamento só consegue pensar o novo em uma conexão imprevisível e absolutamente contingente. Isto é, assumir que o novo não pode ser voluntariamente construído.

Em sentido forte, o pensamento já não se liga com uma vontade de verdade abstrata e universal, mas se relaciona a "uma nova imagem do pensamento [que] significa inicialmente o seguinte: o verdadeiro não é elemento do pensamento. 0 elemento do pensamento é o sentido e o valor." (DELEUZE, 1976, p. 49). Sentido, não por acaso, 
que remete ao significado, mas também à direção e ao sensível. "O conceito de verdade só se determina em função de uma tipologia pluralista. E a tipologia começa por uma topologia” (DELEUZE, 1976, p. 50). Topologia que faz um anúncio: "pensar depende de certas coordenadas.” (DELEUZE, 1976, p. 52). Coordenadas variáveis que, em constante processo de mudança, indicam quanto o pensamento tem de espacial.

É desde essa dimensão espacial que a verdade é rearranjada. "Temos as verdades que merecemos de acordo com o lugar onde colocamos nossa existência, a hora em que estamos despertos, o elemento que frequentamos." (DELEUZE, 1976, p. 52). Essa verdade situada, ou localizada, sustenta uma diferença que não pode ser colonizada. Isso porque, "há diferentes perspectivas de diferentes mundos - e não visões diferentes de um mesmo mundo" (COSTA, 2014, p. 71).

Significa dizer que a relatividade da verdade não é o mesmo que a verdade do relativo. Não se trata de mais um "relativismo, isto é, afırmação de uma relatividade do verdadeiro, mas um relacionalismo, pelo qual se afırma que a verdade do relativo é a relação." (VIVEIROS DE CASTRO, 2002, p. 129). E o espaço, outra vez, aparece como elemento ativo nessa composição.

Portanto, se o espaço pode ser pensado como produto de inter-relações (MASSEY, 2004, 2012, 2015), ele aparece como a dimensão privilegiada na qual ontologia e epistemologia se confundem; como componente conceitual (DELEUZE; GUATTARI, 2010) indomável que não se submete à linguagem da identidade e da representação - correlatas às ideias de modelo e cópia.

0 espaço é diferença em si, aquilo que está em constante mudança, tendo, por isso mesmo, excelência disruptiva. Nesse sentido, currículo, conhecimento e espaço mostramse como uma composição, literalmente, explosiva. Uma explosão que gera uma abertura. É afirmação de que o conhecimento, quando é pensado desde seus laços inter-relacionais, não requer que a cópia seja idêntica ao modelo para ser verdadeira.

\section{Referências}

ALVES, Nilda. Imagens das escolas: sobre redes de conhecimentos e currículos escolares. Educar, Curitiba, n. 17, p. 53-62, 2001.

BIESTA, Gert. Boa educação na era da mensuração. Cadernos de Pesquisa, São Paulo, v. 27, n. 147, p. 808-825, set./dez. 2012.

BUTLER, Judith. A vida psíquica do poder: teorias de sujeição. Belo Horizonte: Autêntica, 2017.

BUTLER, Judith. Deshacer el género. Buenos Aires: Paidós, 2004.

BUTLER, Judith. 0 que é a crítica? Um ensaio sobrea virtude de Foucault. Cadernos de Ética e Filosofia Política, São Paulo, n. 22, p. 159-179, 2013.

BYRNE, Deirdre. The top, the bottom and the middle: space, class and gender in Metropolis. Literator, Johanesburgo, v. 24, n. 3, p. 1-14, nov. 2003. Disponível em: https://literator.org.za/index.php/literator/ article/view/298/271. Acesso em: dez. 2018. 
COSTA, Claudia Lima. Equivocação, tradução e interseccionalidade performativa: observações sobre ética e prática feministas descoloniais. In: BIDASECA, Karina et al. (org.). Legados, genealogías y memorias poscoloniales: escrituras fronterizas desde el Sur. Buenos Aires: Godot, 2014. p. 273-307.

DELEUZE, Gilles. Bergsonismo. São Paulo: 34, 1999.

DELEUZE, Gilles. Nietzsche e a filosofia. Rio de Janeiro: Rio, 1976.

DELEUZE, Gilles; GUATTARI, Félix. Mil Platôs: capitalismo e esquizofrenia. v. 1. São Paulo: 34, 2011.

DELEUZE, Gilles; GUATTARI, Félix. 0 que é a filosofia? São Paulo: 34, 2010.

DELEUZE, Gilles; PARNET, Claire. Diálogos. São Paulo: Escuta, 1998.

DERRIDA, Jacques. Gramatologia. Tradução de Miriam Chnaiderman e Renato Janine Ribeiro. São Paulo: Perspectiva. 1973.

DIDI-HUBERMAN, Georges. Quando as imagens tocam o real. Revista da Pós EBA/UFMG, Belo Horizonte, v. 2, n. 4, p. 204-2019, nov. 2012. Disponível em: https://eba.ufmg.br/revistapos/index.php/pos/article/ download/60/62. Acesso em: dez. 2018.

DOSTOIÉVSKI, Fiódor. Memórias do subsolo. Rio de Janeiro: 34, 2009.

ESCOBAR, Arturo. Sentipensar con la tierra: las luchas territoriales y la dimensión ontológica de las epistemologías del Sur. Revista de Antropología Iberoamericana, Madrid, v. 11, n. 1, p. 11-32, jan./abr. 2016.

FOUCAULT, Michel. Microfísica do poder. Rio de Janeiro: Paz e Terra, 2014.

FOUCAULT, Michel. 0 corpo utópico, as heterotopias. São Paulo: n-1, 2013.

FOUCAULT, Michel. Outros espaços. In: FOUCAULT, Michel. Ditos e escritos IIII. Rio de Janeiro: Forense Universitária, 2001. p. 411-422.

FRITZ LANG (dir.). Metropolis. Produzido por: Erich Pommer. Berlim: Universum Film Aktien Gesellschaft, 1927.

GABRIEL, Carmen Teresa; ROCHA, Ana Angelita. Seleção do conhecimento como operação hegemônica. ETD, Campinas, v. 19, p. 844-863, 2017.

HAESBAERT, Rogério. Por amor aos lugares. Rio de Janeiro: Bertrand Brasil, 2017.

HARAWAY, Donna. Saberes localizados: a questão da ciência para o feminismo e o privilégio da perspectiva parcial. Cadernos Pagu, Campinas, n. 5, p. 7-42, 1995.

INGOLD, Tim. Estar vivo: ensaios sobre movimento, conhecimento e descrição. Petrópolis: Vozes, 2015. 
LACLAU, Ernesto. Misticismo, retorica y política. Buenos Aires: Fondo de Cultura Económica, 2000.

LAPOUJADE, David. Deleuze, os movimentos aberrantes. São Paulo: n-1, 2017.

MACEDO, Elizabeth. Currículo como espaço-tempo de fronteira cultural. Revista Brasileira de Educação, Rio de Janeiro, v. 11, n. 32, p. 285-286, maio/ago. 2006.

MACEDO, Elizabeth. Mas a escola não tem que ensinar? Conhecimento, reconhecimento e alteridade na teoria do currículo. Currículo sem Fronteiras, Pelotas, v. 17, n. 3, p. 539-554, set./dez. 2017.

MARCHART, Olivier. El pensamiento político posfundacional: la diferencia política em Nancy, Lefort, Badiou y Laclau. Buenos Aires: Fondo de Cultura Económica, 2009.

MASSEY, Doreen. Algunos tiempos de espacio. In: ALBET, Abel; BENACH, Núria. Doreen Massey: un sentido global del lugar. Barcelona: Icaria, 2012. p. 182-196.

MASSEY, Doreen. A mente geográfica. GE0graphia, São Paulo, v. 19, n. 40, p. 36-40, 2017.

MASSEY, Doreen. Filosofia e política da espacialidade: algumas considerações. GEOgraphia, Niterói, v. 6, n. 12, p. 7-23, 2004.

MASSEY, Doreen. Pelo espaço: uma nova política da espacialidade. Rio de Janeiro: Bertrand Brasil, 2015.

MLLLER, Janet. Teorização do currículo como antídoto contra a cultura da testagem. E-curriculum, Niterói, v. 12, n. 3, p. 2043-2063, ago./dez. 2014.

NIETZSCHE, Friedrich Willhelm. Obras incompletas. São Paulo: Abril, 1978.

NIETZSCHE, Friedrich Willhelm. Para além do bem e do mal. São Paulo: Martin Claret, 2015.

PESSANHA, Fábio Santana. A hermenêutica do mar: um estudo sobre a poética de Virgílio de Lemos. Rio de Janeiro: Tempo Brasileiro, 2013.

PINAR, William. Estudos curriculares: ensaios selecionados. Seleção, organização e revisão técnica de Alice Casimiro Lopes e Elizabeth Macedo. São Paulo: Cortez, 2016.

PINAR, William. Multiculturalismo malicioso. Currículo sem Fronteiras, Pelotas, v. 9, n. 2, p. 149- 168, jul./dez. 2009.

RANNIERY, Thiago Moreira de Oliveira. Mapas, dança, desenhos: a cartografia como método de pesquisa em educação. Pro-Posições, Campinas, v. 23, n. 3, p. 159-178, set./dez. 2012.

ROY, Kaustuv. Gradientes de intensidade: 0 espaço háptico deleuziano e os três erres do currículo. Educação \& Realidade, Porto Alegre, v. 27, n. 2, p. 89-109, 2002.

SILVA, Tomaz Tadeu da. Documentos de identidade: uma introdução às teorias do currículo. Belo Horizonte: Autêntica, 2005. 
TEDESCHI, Sirley Lizott; PAVAN, Ruth. Currículo e espistemologia: a descriação da identidade/universalidade e a criação da diferença/multiplicidade. Currículo sem Fronteiras, Porto Alegre, v. 17, n. 3, p. 678-698, set./dez. 2017.

VEIGA-NETO. Alfredo. As duas faces da mesma moeda: heterotopias e emplazamientos curriculares. Educação em Revista, Belo Horizonte, v. 45. p. 249-264, jun. 2007.

VEIGA-NETO, Alfredo. Currículo: um desvio à direita ou delírios avaliatórios? [Conferência]. In: COLÓQUIO SOBRE QUESTÕES CURRICULARES, 10., 2002 e COLÓQUIO LUSO-BRASILEIRO DE CURRÍCULO, 6., 2002, Belo Horizonte. Anais... Belo Horizonte: UFMG, 2002. p. 1-15.

VEIGA-NETO, Alfredo. De geometrias, currículo e diferenças. Educação \& Sociedade, Campinas, n. 79, p. 163-186, ago. 2002.

VIVEIROS DE CASTRO, Eduardo. 0 nativo relativo. Mana, Rio de Janeiro, v. 8. n. 1, p. 113-148, 2002.

YOUNG, Michael (org.). Knowledge and control: new directions in the sociology of education. London: Collier-Macmillan, 1971.

YOUNG, Michael. Para que servem as escolas? Educação \& Sociedade, Campinas, v. 28, n. 101, p. 1287 1302, 2007.

YOUNG, Michael F. D. Superando a crise na teoria do currículo: uma abordagem baseada no conhecimento. Cadernos Cenpec, São Paulo, v. 3, n. 2, p. 225-250, 2013.

YOUNG, Michael. Teoria do currículo: o que é e por que é importante. Cadernos de Pesquisa, São Paulo, v. 44, n. 151, p. 190-202, 2014.

ZOURABICHVILI, François. Deleuze: uma filosofia do acontecimento. São Paulo: 34, 2016.

Recebido em: 09.02.2019

Aprovado em: 08.05.2019

Ana Angelita Rocha é professora (Adjunto III) do Departamento de Didática da Faculdade de Educação na Universidade Federal do Rio de Janeiro (UFRJ) e integra o Núcleo de Estudos do Currículo, na mesma instituição, e o Núcleo de Estudos sobre Regionalização e Globalização, na Universidade Federal Fluminense. Tem graduação em geografia pela Universidade do Estado do Rio de Janeiro (2004) e mestrado e doutorado em educação pela Universidade Federal do Rio de Janeiro (2008, 2013).

Ricardo Scofano Medeiros é doutorando (bolsista CAPES) pelo PPGE e integrante do Bafo! (Bando de Estudos e Pesquisas em Currículo, Ética e Diferença), coordenado pelo Prof. Dr. Thiago Ranniery. É licenciado em Geografia pela Universidade Federal do Rio de Janeiro (2016) e mestre em Educação pela mesma instituição (2019). 